\title{
Chlorophyll Breakdown - How Chemistry Has Helped to Decipher a Striking Biological Enigma
}

\section{Bernhard Kräutler* \\ Institute of Organic Chemistry and Centre of Molecular Biosciences, University of Innsbruck, Innrain 80/82, 6020 Innsbruck, Austria \\ bernhard.kraeutler@uibk.ac.at}

Dedicated to Professor Franz-Peter Monforts on the occasion of his $70^{\text {th }}$ birthday.

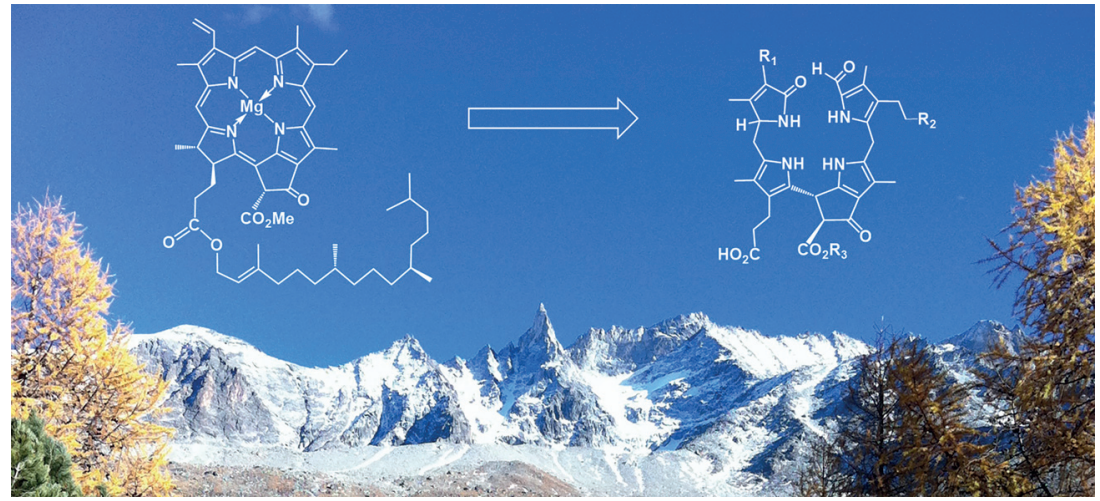

Received: 07.08.2018

Accepted after revision: 20.09.2018

Published online: 31.10 .2018

DOI: 10.1055/s-0037-1611063; Art ID: st-2018-a0501-a

License terms: CCO

Abstract How the fall colors arise and how chlorophyll (Chl) breakdown occurs in higher plants has remained enigmatic until three decades ago. Fundamental insights into this fascinating puzzle have been gained, meanwhile, by basic contributions from plant biology and chemistry. This short review is a personal account of key advances from synthetic, mechanistic, and structural chemistry that led to the discovery of the bilin-type $\mathrm{Chl}$ catabolites and helped elucidate the metabolic processes that generated them from Chl.

1 Introduction

2 Discovery and Structure Elucidation of a First Non-Green Chl Catabolite

3 Structure Elucidation of Fleetingly Existent Blue-Fluorescent Chl Catabolites

4 The Red Chl Catabolite - Key Ring-Opened Tetrapyrrole Accessed by Partial Synthesis

5 Synthesis of 'Primary' Fluorescent Chl Catabolites by Reduction of Red Chl Catabolite

6 Nonfluorescent Chl Catabolites from Isomerization of Fluorescent Chl Catabolites

7 Persistent Fluorescent Chl Catabolites and Blue-Luminescent Bananas

8 Discovery, Structure Elucidation, and Biological Formation of Dioxobilin-Type Chl Catabolites

9 Occurrence, Partial Synthesis, and Structure of Phyllochromobilins, the Colored Bilin-Type Chl Catabolites

10 Conclusion and Outlook

Keywords antioxidants, bilin, catabolite, chlorophyll, fluorescence, glycoside, heterocycles, pigments, porphyrinoids, phyllobilin, senescence, tetrapyrroles

\section{Introduction}

The appearance of the fall colors is an enchanting and puzzling phenomenon. The widespread disappearance of chlorophyll $(\mathrm{Chl})$ in autumn and the re-greening of the veg- etation in spring are probably the most visual signs of life, observable on Earth from outer space. ${ }^{1}$ Indeed, the annual apparent 'recycling' of the green pigment $\mathrm{Chl}$ is a massive biological process involving about 1000 million tons, worldwide, and occurring by seasonally alternating de novo $\mathrm{Chl}$ biosynthesis and Chl degradation. ${ }^{2}$ Strikingly, until about 30 years ago $\mathrm{Chl}$ seemed to disappear without leaving a trace, as non-green products of $\mathrm{Chl}$ breakdown remained elusive. ${ }^{2,3}$ In fact, all searches for genuine Chl catabolites were futile, since they concentrated on the detection of colored remains of the Chls. However, as is now well known, Chl breakdown products in higher plants accumulate as colorless linear tetrapyrroles, primarily. ${ }^{1,4-7}$ All the same, the bilin-type Chl catabolites, named phyllobilins (PBs), ${ }^{8}$ turn out to be remarkably related, structurally, to bilins, ${ }^{9}$ the colored products from heme breakdown. ${ }^{10}$

\section{Discovery and Structure Elucidation of a First Non-Green Chl Catabolite}

Chl breakdown has for a long time been considered to play a particular role in the recuperation of nitrogen. ${ }^{3}$ First traces of non-green $\mathrm{Chl}$ breakdown products were traced by Matile, Thomas and coworkers by comparing the pigment pattern of senescent leaves of wild type Festuca pratensis with those in 'stay green' mutants of this grass. ${ }^{11}$ Remarkably, colorless compounds could be spotted in the wild type that were absent in the green mutant, and which were presumed to represent Chl catabolites. These polar compounds were called 'rusty pigments', as they rapidly converted into rust-colored products. ${ }^{12}$ We learned to isolate one such 'rusty pigment' without degradation and color formation, and elucidated its chemical constitution in 1991 with the help of heteronuclear NMR spectroscopy and soft ionization mass spectrometry. ${ }^{4,13}$ It turned out to be fruitful, to solve 
the desired structure directly by purely spectroscopic means, ${ }^{4}$ rather than submitting this polar Chl catabolite to chemical modifications, e.g., in order to decrease its polarity.

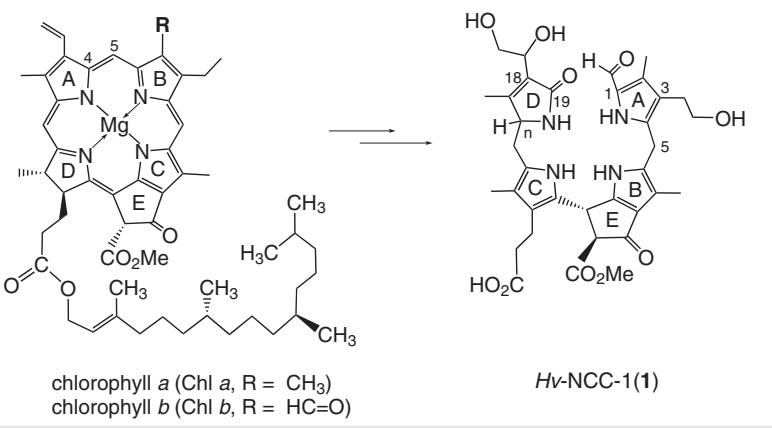

Scheme 1 Structural formulae of chlorophylls $a$ and $b$ and of Hv-NCC-1 (1)

The colorless 'rusty pigment' from de-greened leaves of barley (Hordeum vulgare) was unambiguously revealed to be a bilane-type linear tetrapyrrole that carried structural hallmarks of the Chls, such as their characteristic ring C/Eportion. ${ }^{4}$ It was classified as a nonfluorescent $\mathrm{Chl}$ catabolite (NCC) and given the phenomenological name $H v$-NCC-1 (1). ${ }^{14}$ More recently, it was classified semisystematically as a 1-formyl-19-oxo-16,19-dihydrophyllobilane, ${ }^{5,8}$ see Scheme 1 . The structure of $\mathbf{1}$ indicated oxidative ring opening of the Chl macrocycle at the 'northern' meso position, between $\mathrm{C} 4$ and $\mathrm{C} 5$, thus, representing a 4,5-secophytoporphyrinoid. ${ }^{4,13}$ This cleavage site contrasted with all expectations from Chl chemistry, ${ }^{15}$ but turned out to be strikingly reminiscent of the site of ring opening in heme breakdown. ${ }^{16}$ However, in contrast to the typical colored bilins from heme breakdown, ${ }^{9,16}$ the meso-carbon $\mathrm{C} 5$ of Chl $a$ was retained in the formyl group of the NCC 1 , and its three remaining meso positions were saturated. Additional peripheral polar functionality of $\mathbf{1}$ pointed to puzzling catabolic reactions in its formation, raising further questions to its biochemical formation and to the general relevance of its structure for the general problem of Chl breakdown in higher plants.

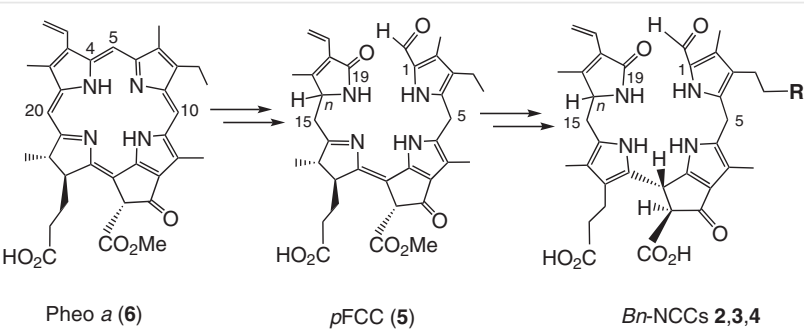

Scheme 2 Structural formulae of Pheo a (6), pFCC (5), and of NCCs 2 ( $R=$ malonate), 3 ( $R=1$ '- $\beta$-D-glucopyranose), and $4(R=O H)$ from senescent leaves of oil seed rape (Brassica napus)

\section{Structure Elucidation of Fleetingly Exis- tent Blue-Fluorescent Chl Catabolites}

The repeated observation of fleetingly existent blue-fluorescent compounds alongside of the NCCs in extracts of senescent leaves suggested their relevance in Chl breakdown. ${ }^{17}$ In vitro experiments by Hörtensteiner and Matile showed the requirement for molecular oxygen and identified the Mg-free and dephytylated Chl derivative pheophorbide $a$ (Pheo $a, 6$ ) as a precursor for the presumed $\mathrm{Chl}$ catabolites. ${ }^{18}$ From a preparation with Pheo $a$ as the substrate by using an enzyme active extract of senescent leaves of oil seed rape (Brassica napus), a rather instable blue-fluorescent compound became available in small quantities, believed to be a Chl catabolite. By spectroscopic means its structure was, again, revealed as a linear tetrapyrrole, ${ }^{19}$ closely related to $\mathbf{1}$, and to three polar Brassica napus NCCs that had meanwhile been found in senescent cotyledons of oil seed rape ${ }^{20}$ (typical UV/Vis absorption spectra are collected in the reviews $\left.{ }^{5,8}\right)$. The fluorescent compound was, therefore, phenomenologically named Bn-FCC-2 (5) and classified as a fluorescent Chl catabolite (FCC) (see Scheme 2). ${ }^{19}$ The chemical constitution of $\mathbf{5}$ supported its hypothetical role as a biological precursor of the Bn-NCCs 2-4. The molecular formula of the FCC $\mathbf{5}$ also indicated a close relationship to $\mathbf{6}$, involving the mere formal incorporation of two oxygen atoms and four hydrogen atoms in the course of the presumed formation of $\mathbf{5}$ from $\mathbf{6}$. Hence, the moderately polar FCC $\mathbf{5}$ was deduced to represent a straight forward

\section{Biographical Sketch}

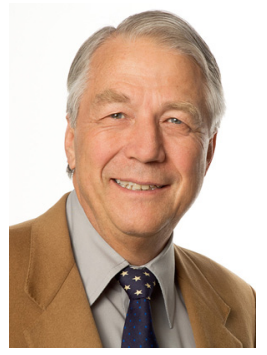

Bernhard Kräutler studied chemistry at the ETH in Zürich, where he received his $\mathrm{PhD}$ working with Prof. Albert Eschenmoser. After postdoctoral studies with Prof. Allen J. Bard (University of Texas, Austin) and with Prof. Nicholas J. Turro (Co- lumbia University, New York City) he returned to the ETH to start his own research group. In the fall of 1985 he was a visiting Professor at the Roger Adams Labs of the University of Illinois. In 1991 he became Full Professor of Organic Chemistry at the
University of Innsbruck, where he has been Professor Emeritus since October 2015. His current research interests include the chemistry and chemical biology of chlorophyll and vitamin B12. 
('primary') product of the breakdown of $\mathbf{6}$, and was assigned the specific role as 'primary' FCC $(p F C C) .{ }^{19}$ As the relative configuration of the three stereocenters of $p \mathrm{FCC}(\mathbf{5})$ at $\mathrm{C}^{2}, \mathrm{C} 12$, and $\mathrm{C} 13$ was the same as that in Pheo $a(\mathbf{6})$, their absolute configuration was also inferred to be retained. Hence, pFCC (5) is a $8^{2} R, 12 S, 13 S, 10 Z, 16 n$-1-formyl-19-oxo$19,12,13,16$-tetrahydrophyllobilene- $b .^{5,8}$

However, in extracts of senescent leaves of sweet pepper (Capsicum annuum) a different fluorescent Chl catabolite (Ca-FCC-2) was observed, which was identified as an isomer of $p F C C$ (5). Ca-FCC-2 was deduced to display the same (relative) stereochemistry at $\mathrm{C} 8^{2}, \mathrm{C} 12$, and $\mathrm{C} 13$, but to differ from $p \mathrm{FCC}(\mathbf{5})$ by the configuration at C16. Hence, Ca-FCC-2 was named epi-pFCC (epi-5), with the semisystematic name $8^{2} R, 12 S, 13 S, 10 Z, 16 e p i-1$-formyl-19-oxo$12,13,16,19$-tetrahydrophyllobilene- $b ., 21$ The absolute configuration of $\mathrm{C} 16$ of $p \mathrm{FCC}(\mathbf{5})$ or of epi-pFCC (epi-5) is not established, so that it is classified provisionally as 'normal $=n$ ' in 5, or as 'epimeric = epi' in epi-5, and in their respective catabolic descendants. ${ }^{5}$

The structural analysis suggested the formation of 'primary' FCCs from Pheo $a(\mathbf{6})$ to involve more than one enzyme and to require the existence of an intermediate, probably less saturated at its 'western' meso position than $\mathbf{5}$ or epi-5. ${ }^{19}$ In analogy to the red excretion products of Chl breakdown of the alga Auxenochlorella protothecoides, characterized structurally in Gossauer's group, ${ }^{22}$ related red linear tetrapyrroles were now taken into consideration as so far elusive intermediates of the Chl breakdown in higher plants (see Scheme 3). ${ }^{19,23}$

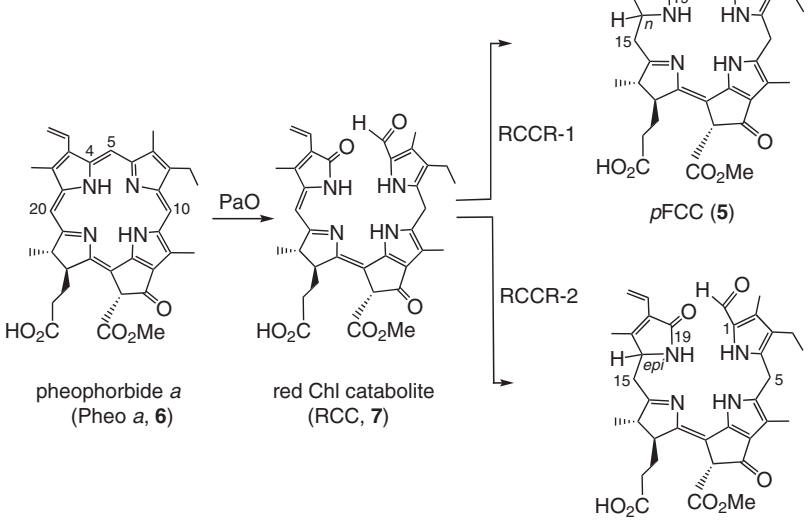

epi-pFCC (epi-5)
Scheme 3 Structural outline of key steps of Chl breakdown. Oxidative cleavage of Pheo $a(\mathbf{6})$ by Pheo $a$ oxygenase (PAO) generates red Chl catabolite (RCC, 7) in enzyme-bound form, which is reduced by RCC reductases (RCCRs) to 'primary' fluorescing Chl catabolites. RCCRs-1 furnish pFCC (5) stereoselectively, RCCRs-2 epi-pFCC (epi-5).

\section{The Red ChI Catabolite - Key Ring-Opened Tetrapyrrole Accessed by Partial Synthesis}

Since a red Chl catabolite was unknown in higher plants, we set out to prepare the likely candidate by partial synthesis from the methyl ester of Pheo $a(\mathbf{6})$, in order to help test the suggested intermediacy of such a red bilin-type Chl catabolite in higher plants. Our synthesis of the presumed red Chl catabolite (RCC, 7) roughly followed a methodology, developed by Iturraspe and Gossauer, for the preparation of the corresponding analogs from the green alga. ${ }^{24}$ For this purpose, 6 was converted into the green $\mathrm{Cd}(\mathrm{II})$-methylpheophorbidate $\mathbf{8}$, which was subsequently subjected to photo-oxidation at $-40{ }^{\circ} \mathrm{C}$, furnishing the corresponding 4,5-secoporphyrinoid Cd complex 9 in about $32 \%$ yield (see Scheme 4). ${ }^{23}$ Reduction of the latter with sodium borohydride at room temperature and work-up of the reaction mixture with dilute hydrochloric acid furnished the red 4,5-secoporphyrinoid Me-7 (as a 3:1 mixture of $8^{2}$-epimers) in $72 \%$ total yield. Under these conditions, (i) the electrophilic meso position between the 'eastern' rings of the 4,5-secoporphyrinoid Cd complex 9 was reduced by the hydride reagent selectively, and (ii) the subsequent acid treatment removed the $\mathrm{Cd}$ ion quantitatively. The main isomer Me-7 was isolated by semipreparative HPLC and shown to exhibit the natural $\beta$-configuration at $\mathrm{C}^{2}$, as deduced from NOE investigations. ${ }^{23}$ The semisynthetic dimethyl ester $\mathbf{M e -} \mathbf{7}^{23}$ was also identified with a dimethyl-ester isolate of a red Chl catabolite from Auxenochlorella protothecoides. ${ }^{25}$ By using pig liver esterase, Me-7 was hydrolyzed highly regioselectively to the remarkably stable RCC (7), ${ }^{23}$ the (then) elusive key red catabolite and precursor of $p F C C$ (5) and epi-pFCC (epi-5).

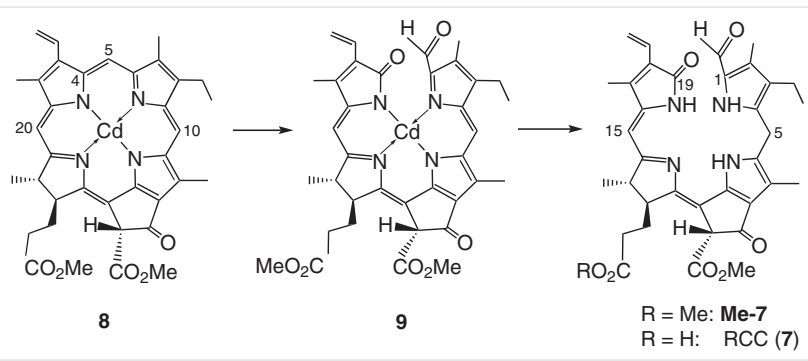

Scheme 4 Photooxydation of the $\mathrm{Cd}$-pheophorbidate $\mathbf{8}$ furnishes the secoporphyrinoid Cd complex 9, from which the RCC methyl ester Me-7 was obtained by $\mathrm{NaBH}_{4}$ reduction. Selective enzymatic hydrolysis of Me-7 furnished RCC (7) nearly quantitatively.

Samples of semisynthetic RCC (7, 82R,12S,13S,10Z,15Z1-formyl-19-oxo-12,13,16,19-tetrahydrophyllobiladiene$b, c)^{5}$ were tested for their presumed central role in Chl breakdown in leaves. Indeed, an extract from senescent barley leaves containing active stroma enzymes converted 7 stereoselectively into $p \mathrm{FCC}(\mathbf{5})$. Predominant conversion of 7 to epi-5 was, likewise, observed with a corresponding 
preparation obtained from sweet pepper. ${ }^{26}$ Furthermore, traces of RCC (7) were now detected in an aerated incubation of Pheo $a$ with chloroplast membranes from senescent sweet pepper cotyledons washed free of stroma components. These in vitro experiments confirmed the relevance of two enzymatic steps involved in the conversion of Pheo $a$ to $p$ FCC (5), with RCC (7) representing the original enzymebound intermediate with a 4,5-seco-porphyrinoid bilintype structure. ${ }^{5,26}$ Meanwhile, the two inferred enzymes have been identified by Hörtensteiner and coworkers as the non-heme iron-dependent enzyme Pheo $a$ oxygenase $(\mathrm{PAO})^{27}$ and the cofactor-free ferredoxin-dependent RCC reductase (RCCR). ${ }^{6,28}$ In fact, two plant-specific lines of RCCRs exist, classified as RCCR-1 and RCCR-2, which produce either $p \mathrm{FCC}(5)$ or epi-pFCC (epi-5), respectively, in a stereoselective way (see Scheme 3). ${ }^{29}$ The oxygen-dependent ringopening of Pheo $a$, catalyzed by PAO, has been scrutinized more closely, by using isotopically labeled $\mathrm{O}_{2}\left({ }^{18,18} \mathrm{O}_{2}\right)$. As shown by mass spectrometry, the isotopic label was only incorporated into the formyl group of 5 (see Scheme 5), indicating the key cleavage of the macro-ring of Pheo $a$ to occur by insertion of one atom of the $\mathrm{O}_{2}$ molecule, characterizing PAO as a monooxygenase. ${ }^{30}$ This enzyme and the downstream phyllobilins are the common key elements of Chl breakdown in higher plants, hence, named the $\mathrm{PAO} /$ phyllobilin pathway. ${ }^{5,31,32}$
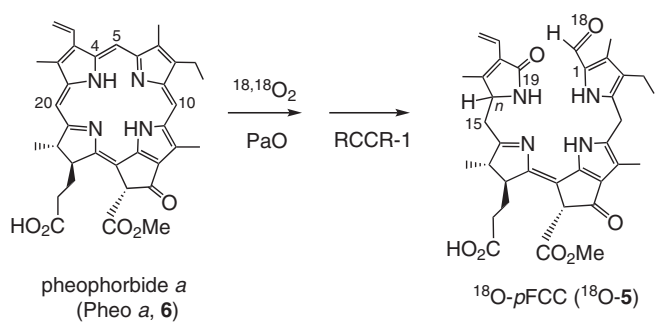

Scheme 5 Enzymatic conversion of Pheo $a$ in the presence of ${ }^{18,18} \mathrm{O}_{2}$ by the monooxygenase $\mathrm{PAO}$ and by the RCC reductase of type RCCR-1 produced ${ }^{18} \mathrm{O}-\mathrm{pFCC}$.

\section{Synthesis of 'Primary' Fluorescent Chl Catabolites by Reduction of Red Chl Catabo- lite}

Samples of semisynthetic red Chl catabolite (RCC, 7) and its methyl ester Me-7 were also used for exploring their chemical conversion into the corresponding 'primary' FCCs or their methyl esters. Electrochemical reduction of semisynthetic Me-7 in a deoxygenated methanolic solution at $1.3 \mathrm{~V}$ vs. a $0.1 \mathrm{~N}$ calomel electrode produced two major FCC methyl ester fractions, besides yellow regioisomers. ${ }^{33}$ The separated fractions of the two pure semisynthetic FCC methyl esters were assigned the structures of methyl esters of $p$ FCC (5) and epi-pFCC (epi-5), on the basis of NMR-spectroscopic analyses. The free catabolite RCC (7) was, likewise, reduced electrochemically at $-1.3 \mathrm{~V}$ vs. $0.1 \mathrm{~N}$ calomel electrode in a deoxygenated methanolic solution containing phenol, which produced roughly equal amounts of the two 'primary' FCCs, 5 and epi-5, as well as their yellow regioisomers, ${ }^{34}$ with a chromophore structure reminiscent of functionality present in some heme-derived bilins ${ }^{9}$ (see Scheme 6 ). Because of their tendency to isomerize in weakly acidic solution (see below), the epimeric FCCs needed to be isolated and stored with due precautions. These electrochemical experiments not only opened up a short preparative route to FCCs (or phyllolumobilins, PluBs), but they also represented first model reactions for the puzzling enzymatic conversion of an RCC (7) to a 'primary' FCC by the cofactorfree RCCRs. Indeed, our studies suggested a mode of action of RCCRs requiring an external supply with electrons and protons, as deduced meanwhile in a range of bilin reductases, ${ }^{35}$ including RCCR from Arabidopsis thaliana. ${ }^{36}$

\section{Nonfluorescent Chl Catabolites from Isomerization of Fluorescent Chl Catabolites}

Comparison of the core structures of FCCs and of natural nonfluorescent Chl catabolites (NCCs or phyllobilanes), indicated them to represent pairs of constitutional isomers and suggested the existence of an isomerization path from

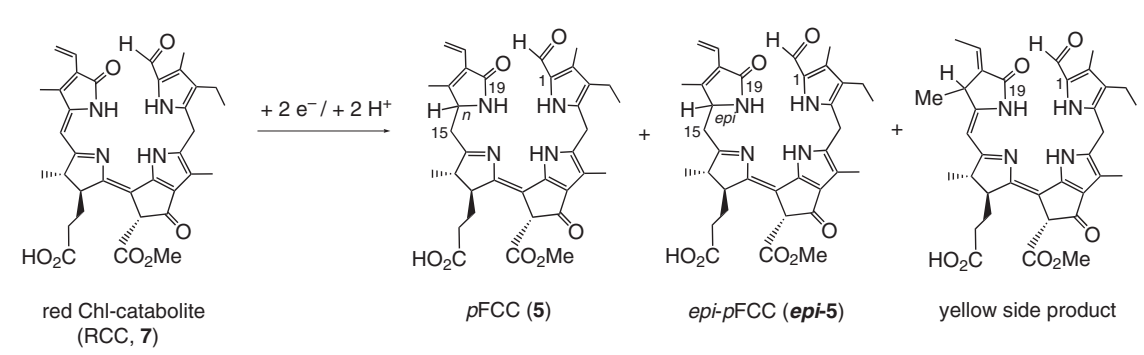

Scheme 6 Electrochemical reduction of the red Chl catabolite (RCC) in MeOH furnished a roughly (1:1) mixture of the colorless PBs pFCC (5) and epipFCC (epi-5), and a yellow constitutional isomer, as a relevant side product. 
FCCs to the corresponding NCCs. This hypothesis was first tested with a sample of authentic epi-5. Indeed, in aqueous solutions the 'primary' FCC epi-5 isomerized stereoselectively to the moderately polar NCC epi-10, named $8^{2} S, 10 R, 16 e p i-1$-formyl-19-oxo-16,19-dihydrophyllobilane (see Scheme 7). The phyllobilane epi-10 was identified with a natural NCC isolated in small amounts from senescent leaves of the deciduous tree Cercidiphyllum japonicum, and named phenomenologically as $\mathrm{Cj}$-NCC- $2 .^{37}$

The crucial stereochemical outcome of the FCC to NCC isomerization, which installs the newly saturated $\mathrm{C} 10$ with $R$-configuration, was ascribed to the critical contribution of the propionic acid function in protonating this prochiral meso-C of typical FCCs by an intramolecular path. This fact, as well as the observed (pH-dependent) overall rates of isomerization of 5 and epi-5 at pH 3.5-7 suggested such a spontaneous chemical process to account for NCC formation under physiological conditions in the acidic vacuoles of the plant cell. ${ }^{37}$ A sequence of tautomerization and epimerization steps was proposed to account for this reaction, which is driven thermodynamically by the isomerization of the characteristic FCC chromophore into the more stable one of an NCC. ${ }^{37}$ Interestingly, the saturated meso position C10 in natural NCCs appears to conform to a common $R$ configuration (as derived from their CD spectra), supporting the general relevance of the isomerization path activated by the propionic acid function of typical natural FCCs. ${ }^{5}$ Indeed, in agreement with their tendency to convert spontaneously to their (more stable) NCC isomers, typical natural FCCs are only fleetingly existent in senescent leaves as intermediates of $\mathrm{Chl}$ breakdown. ${ }^{6}$

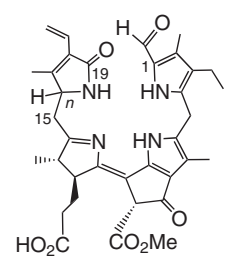

$p F C C(5)$

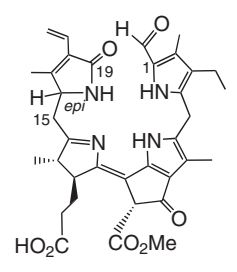

epi-pFCC (epi-5)
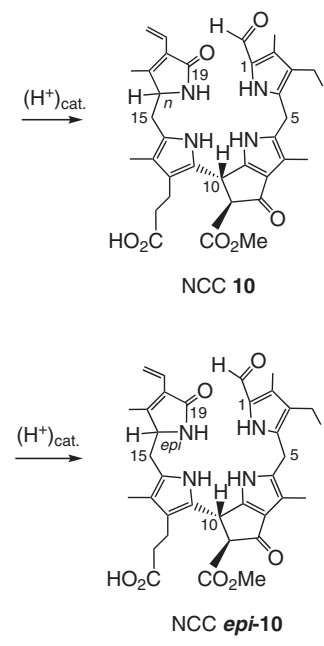

Scheme 7 In weakly acidic solution pFCC (5) and epi-pFCC (epi-5) isomerize stereoselectively to the NCCs $\mathbf{1 0}$ and epi-10, respectively.

In contrast to $p \mathrm{FCC}$ and epi-pFCC, their FCC methyl esters Me-5 and Me-epi-5 were persistent and required strong acid (trifluoroacetic acid), in order to promote their rather stereounselective isomerization to NCC methyl esters. The theoretically complete set of four stereoisomers was obtained, i.e. Me-10 and Me-epi-10, and their C10 epimers Me-ent-10 and Me-ent-epi-10. Thus, the methyl esters of the so far unknown type of enantiomeric NCCs (Me-ent-10 and Me-ent-epi-10) was obtained, as well as the methyl ester (Me-epi-10) of the natural NCC named Cj-NCC-2 (see Scheme 8). ${ }^{34}$ As observed elsewhere, the chiroptical properties of the NCCs were dominated by the effect of the absolute configuration at $\mathrm{C} 10 .{ }^{34}$
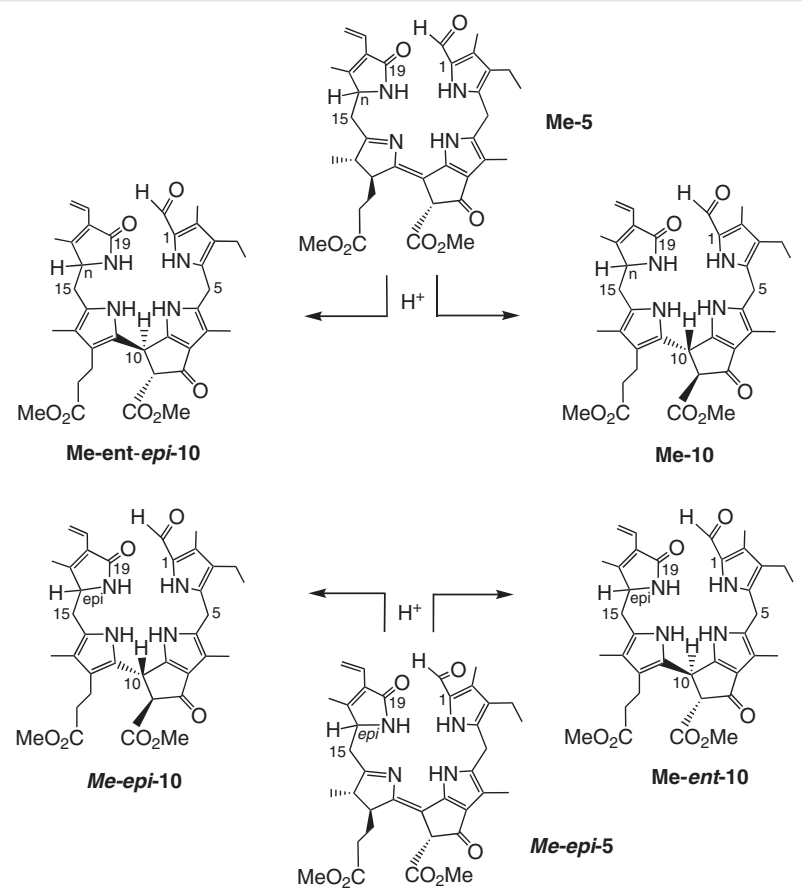

Me-ent-10

$\mathrm{MeO}_{2} \mathrm{C}$

Scheme 8 The isomerization of the synthetic methyl esters Me-5 and Me-epi-5 of pFCC (5) and epi-pFCC (epi-5) to NCCs requires strong acid and shows insignificant stereo-selectivity.

On the basis of the list of roughly thirty structurally different natural NCCs, known at present, ${ }^{5}$ a corresponding number of natural FCCs would, hence, be expected to occur in senescent plants as short-lived intermediates of Chl breakdown. So far only six of the rather unstable natural FCCs have been characterized structurally that carry the critical free propionic acid function. ${ }^{5}$ However, the existence of two epimeric 'primary' FCCs, $\mathbf{5}$ and $\boldsymbol{e p i - 5}$, opens up a path to the two corresponding epimeric lines of the natural NCCs. ${ }^{5}$ The stereochemical classification of a range of NCCs and of other downstream phyllobilins (PBs) as ' $n$ ' or 'epi' was achieved by the identification of key NCCs, which were first screened by mass spectrometry ${ }^{38}$ and UV/Vis spectroscopy ${ }^{39}$ with known NCC reference compounds (further NMR-spectral and HPLC-based comparison). Thus, the assignment of the structure, e.g., of NCCs from spinach leaves as belonging to the 'epi'-series was secured by identifying the polar So-NCC-2 (epi-1) as C16-epimer of $1(H v-$ 
NCC-1). ${ }^{13,40,41}$ For this purpose, an additional stereounselective synthesis of a pair of reference compounds with the common 1,2-dihydroxyethyl side chain of the two NCCs was carried out. It was achieved by regioselective $\mathrm{OsO}_{4}$ oxidation of the exocyclic vinyl group ${ }^{41}$ of $\mathrm{Cj}$-NCC-1 (epi-11, $8^{2} S, 10 R, 16 e p i-3^{2}$-hydroxy-1-formyl-19-oxo-16,19-dihydrophyllobilane), the 'model' NCC of the 'epi-series' (see Scheme 9). ${ }^{42,43}$

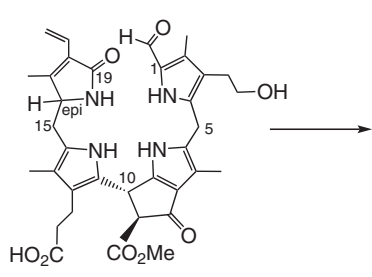

Cj-NCC-1 (epi-11)

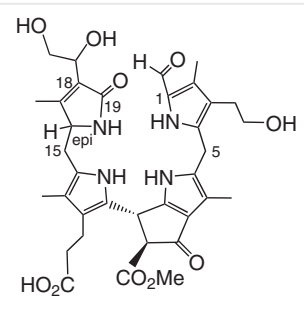

So-NCC-2 (epi-1)
Scheme 9 Stereounselective dihydroxylation of $\mathrm{Cj}_{-} \mathrm{NCC}-1$ (epi-11) with $\mathrm{OsO}_{4}$ furnished a roughly $1: 1$ mixture of So-NCC-2 (epi-1), the C16-epimer of Hv-NCC-1 (1), and its uncharacterized $18^{1}$-epimer.

In the three NCCs from senescent oil seed rape leaves (the Bn-NCCs 2-4) a $\beta$-keto-carboxylic acid function (from eventual hydrolysis of the original $\beta$-keto methyl ester function of $p F C C$ ) turned out to be surprisingly stable and spontaneous decarboxylation did not occur with any one of them. $^{20}$ Furthermore, from enzymatic hydrolysis of the methyl ester function of epi-11 the semisynthetic carboxylic acid analogue epi-12 was obtained, also found in senescent leaves of spinach as So-NCC-3. ${ }^{40}$ Decarboxylation of the $\beta$-keto-carboxylate epi-12 was remarkably slow and required heating with dilute sulfuric acid to give the corresponding 'pyro'-NCC epi-13 (see Scheme 10), a 10R,16-epi$3^{2}$-hydroxy-8 ${ }^{2}$-decarbomethoxy-1-formyl-19-oxo-16,19dihydrophyllobilane. ${ }^{44}$

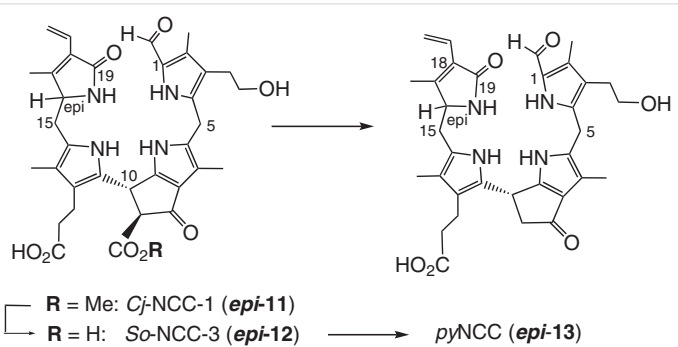

Scheme 10 Preparation of pyNCC (epi-13) by forced decarboxylation of epi-12

\section{Persistent Fluorescent Chl Catabolites and Blue- Luminescent Bananas}

In the peels of ripening bananas a variety of strikingly persistent natural FCCs accumulates and give the ripe banana a blue glow. ${ }^{45,46,47}$ Spectroscopic analysis of such banana FCCs revealed the presence of propionate esters as their new structural feature, as, e.g., in Ma-FCC-56 (epi-14) (see Figure 1). ${ }^{45,47}$

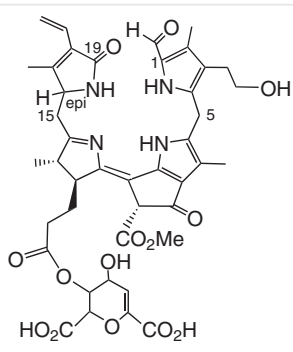

Ma-FCC-56 (epi-14)

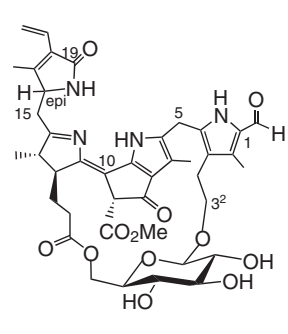

$V v$-FCC-55 (epi-15)
Figure 1 Structural formulae of Ma-FCC-56 (epi-14), a hypermodified FCC (hmFCC), and of $V v$-FCC-55 (epi-15), a bicyclo-FCC (bcFCC) with 1 ' $\beta, 6^{\prime}$-D-glucopyranosyl bridge

Indeed, this type of natural ester modification deactivates FCCs against their isomerization to NCCs and makes such 'hypermodified' FCCs ( $h m$ FCCs) persistent, so that they may accumulate in ripening fruit, ${ }^{45,48}$ as well as in senescent leaves of some evergreens. ${ }^{49,50}$ A new basic variant of the $h m$ FCCs was discovered recently in $V v$-FCC-55 (epi-15) isolated in senescent leaves of grapevine (Vitis vinifera). It exhibited two-fold attachment of a sugar unit furnishing a 'bicyclo'-FCC ( $b c$ FCC) with a $\beta$-glycopyranosyl linker bridging the propionate side chain extending from $\mathrm{C} 12$ and the hydroxyethyl substituent extending from C3 of the phyllobilin core. ${ }^{51}$ Formation of $h m F C C s$ and $b c F C C s$ indicates biosynthetic investments in ripening fruit and in senescent leaves that suggests still unknown biological roles of such PBs in the plants. 5,51,52

\section{Discovery, Structure Elucidation, and Biological Formation of Dioxobilin-Type Chl Catabolites}

The absorption of colorless PBs at around $320 \mathrm{~nm}$, which is due to the characteristic formyl-pyrrole unit of the PBs identified until about 2008,53 allowed on-line detection of PBs by routine HPLC analyses of extracts of senescent leaves, ${ }^{13,20,40,41,54}$ of vegetables, ${ }^{40,55}$ and ripe fruit. ${ }^{56,57}$ Fluorescence at $450 \mathrm{~nm}$ was also used for on-line identification in more recent analyses. ${ }^{45,49}$ The analytical setup was extended to detection at $250 \mathrm{~nm}$, when Losey and Engel reported on two epimeric nonfluorescent 'urobilinogenoidic' Chl catabolites (or DNCCs, see below) from senescent leaves 
of barley that absorbed little at $320 \mathrm{~nm} .{ }^{58}$ Likewise, in extracts of senescent leaves of Norway maple, NCCs were absent and the colorless and nonfluorescent dioxobilin-type NCC (DNCC) 16 was found instead. ${ }^{59}$ Interestingly, the maple DNCC 16 was a chiroptically distinct stereoisomer (possibly the enantiomer) of one of the earlier described 'urobilinogenoidic' Chl catabolites from barley leaves (see Figure 2). ${ }^{58}$ This curious finding contrasted with the presumed formation of DNCCs from NCCs, ${ }^{58}$ and raised the question of the biological formation of dioxobilin-type PBs.

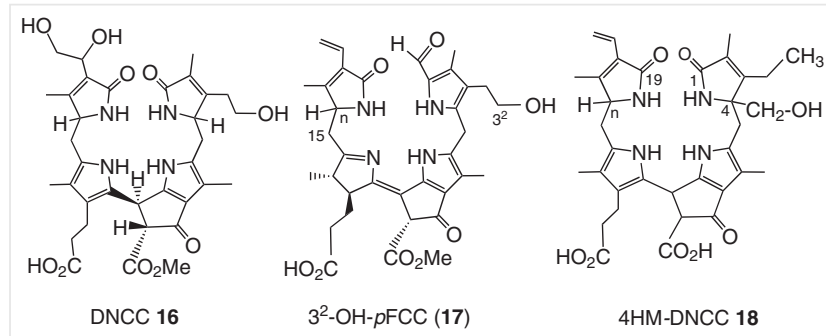

Figure 2 Formulae of the DNCC 16 from senescent leaves of Norway maple, of the key FCC, $3^{2}$-hydroxo-pFCC (17), and of At-4HM-DNCC-41 (18), a remarkable, 4-hydoxymethylated DNCC from senescent leaves of $A$. thaliana

In collaboration with the Hörtensteiner lab, dioxobilintype NCCs (DNCCS) were established as the dominant colorless PBs in senescent leaves of $A$. thaliana, and the cytochrome-P450 enzyme CYP89A9 was shown to be crucial for their formation. ${ }^{60}$ CYP89A9 is a new (heme-dependent) P450-type oxygenase that deformylates the ring $\mathrm{A} \alpha-$ formyl-pyrrole unit of relatively apolar FCCs oxidatively, generating fleetingly existent dioxobilin-type FCCs (DFCCs or $12 S, 13 S, 10 Z-1,19$-dioxo-1,4,12,13,16,19-hexahydrophyllobilenes- $b) .{ }^{60}$ Dioxobilin-type PBs have, hence, been classified as type-II PBs, as they are generated from the first produced formyl-oxobilin-type PBs, or type-I PBs, in the course of the PAO/phyllobilin pathway of Chl breakdown of higher plants. ${ }^{8}$ The oxidative deformylation by CYP89A9 was first tested with the $p F C C(5)$ itself and resulted in a mixture of fluorescent dioxobilin-type PBs (FDCCs). ${ }^{60}$ Amazingly hydroxymethylated iso-DNCCs, such as the 4HM-DNCC 18 (see Figure 2), were among the downstream dioxobilintype products generated from $p F C C(5)$ in vivo, as deduced by heteronuclear NMR spectroscopy. ${ }^{61}$

However, a preferred FCC-substrate for CYP89A9 was $3^{2}$ hydroxo-pFCC (17), ${ }^{62}$ which is generated from $\mathbf{5}$ by the hydroxylase TIC55. ${ }^{63}$ (see Scheme 11). Deformylation of $\mathbf{1 7}$ furnished the intermediate DFCC Me-19. The stereoselective isomerization of the more polar and hardly detectable fluorescent type-II hydrolysis product DFCC 19 to the main nonfluorescent DNCC $\mathbf{2 0}$ of $A$. thaliana (named At-DNCC33), was elucidated by a chemical in vitro experiment. This

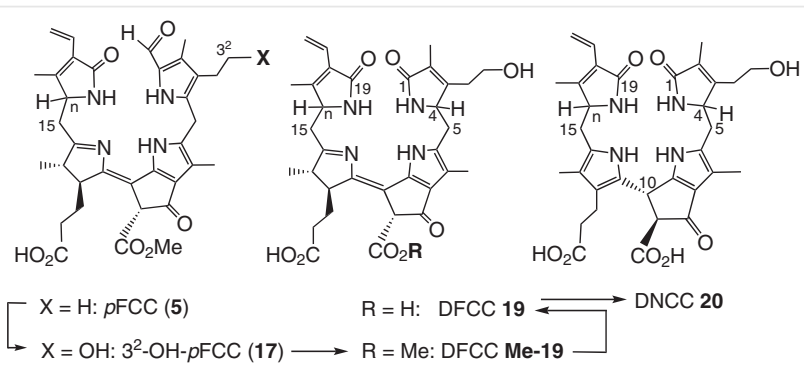

Scheme 11 The HO-pFCC (17) is generated from $\mathbf{5}$ by the hydroxylase TIC55, and is deformylated by CYP89A9 to the DFCC Me-19, which is hydrolyzed enzymatically (by the methylesterase MES-16) to the fleetingly existent DFCC 19. The DFCC 19 isomerizes spontaneously in weakly acidic medium to DNCC 20.

isomerization was proposed to occur by the same basic mechanism, ${ }^{64}$ as described for the analogous FCC isomerization to NCCs (see Scheme 11). ${ }^{37}$ In senescent leaves of grapevine (Vitis vinifera) the colorless PBs are of the 'epitype' and the main DNCC in such leaves is a C16-epi analogue of the DNCCs of $A$. thaliana. ${ }^{51}$ Indeed, DNCCs functionalized at the $3^{2}$-position, such as $\mathbf{2 0}$, appear to be widespread nonfluorescent type-II PBs and have been detected in recent years in a range of senescent leaves, ${ }^{51,59,60,65,66}$ in some vegetables, ${ }^{55}$ and also in fruit. ${ }^{67}$ DNCCs more directly derived from $p \mathrm{FCC}(\mathbf{5})$ by oxidative deformylation and their hydroxymethylated analogs (such as the 4HM-DNCC 18) are much less abundant in senescent leaves. ${ }^{61,68}$

\section{Occurrence, Partial Synthesis, and Struc- ture of Phyllochromobilins, the Colored Bilin- Type Chl Catabolites}

The original classification of $H v$-NCC-1 (1) as a 'rusty pigment' referred to the readily occurring transformations of NCCs to colored compounds (typical UV/Vis absorption spectra are collected in the reviews ${ }^{5,8}$ ). Chemical oxidation of Cj-NCC-1 (epi-11) by DDQ at low temperature and workup at room temperature with a short treatment with trifluoroacetic acid produced the yellow bilin-type tetrapyrrole $\mathbf{2 1 Z}$ as main product, characterized as $8^{2} S, 10 R, 15 Z-3^{2}-$ hydroxy-1-formyl-19-oxo-19,N24-dihydrophyllobilene-c, a type-I phylloxanthobilin (PxB) commonly classified as a yellow Chl catabolite (YCC). ${ }^{69}$ The yellow pigment $\mathbf{2 1 Z}$, and its more polar $15 E$-isomer $\mathbf{2 1 E}$, have also been observed in extracts of senescent leaves of $C$. japonicum (and were first given the phenomenological name $C j-Y C C-2$ and $C j$-YCC-1, respectively). ${ }^{70}$ These two PxBs have a chromophore identical to the one present in bilirubin. ${ }^{69,71}$ In methanolic solution they interconvert by $Z / E$-isomerization upon irradiation with day light (see Scheme 12). ${ }^{70}$ 


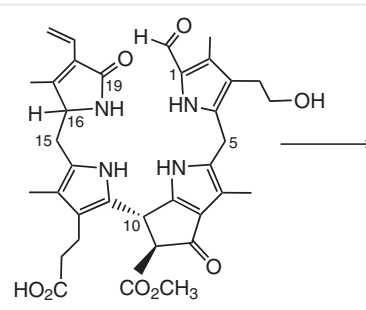

NCC epi-11

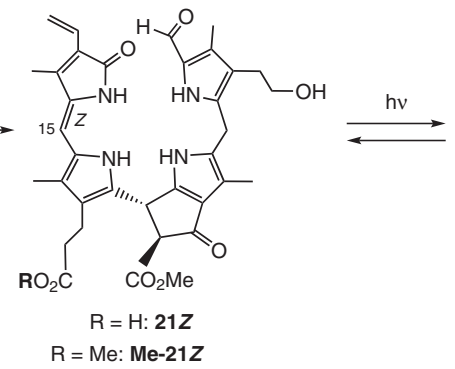

$\mathrm{R}=\mathrm{Me}: \mathrm{Me}-21 Z$

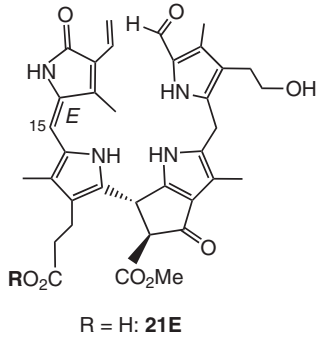

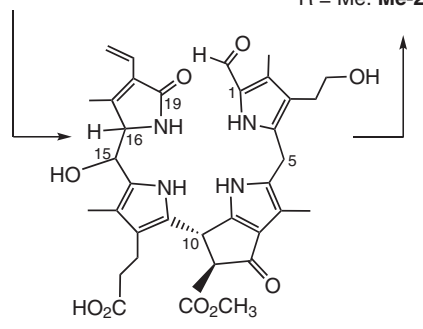

15-OH-epi-11

Scheme 12 The NCC epi-11 is oxidized by chemical oxidants or by a puzzling 'oxidative activity' in leaves to 15-OH-epi-11, from which water is lost readily to furnish the YCC 21Z. YCC $21 Z$ photoisomerizes to the YCC $21 E$ reversibly.

However, $\mathbf{2 1 Z}$ and its methyl ester (Me-21Z) exhibit a remarkably medium-responsive photochemistry, which is due to the tendency of these two type-I 15Z-PxBs to associate to dimers (in a 'hand shake motif) in less polar media, e.g., when dissolved in $\mathrm{CHCl}_{3}$ or in membrane-mimetic micellar detergent solutions. ${ }^{72}$ Photolysis of a solution of $\mathbf{2 1 Z}$ in chloroform led to selective formation of a $C_{2}$-symmetric, unstable [2+2]-cycloadduct that reverted to $\mathbf{2 1 Z}$ cleanly at room temperature. ${ }^{72}$ In dimethylsulfoxide solution $\mathbf{2 1 Z}$ was monomeric and exhibited a weak emission at $493 \mathrm{~nm}$. It bound $\mathrm{Zn}$ ions cleanly in a 2:1 complex, which exhibited a strong red-shifted fluorescence at $538 \mathrm{~nm}$, about 100 times more intense than that of $\mathbf{2 1 Z}$ itself. ${ }^{73}$

Fortunately, the methyl ester Me-21Z furnished single crystals, suitable for X-ray analysis. The crystal analysis confirmed the NMR-based structure determination and showed Me-21Z to associate into H-bonded and $\pi$-stacked dimers in the crystal. ${ }^{72}$ It also allowed for the unambiguous determination of the absolute configuration of the asymmetric carbons $\mathrm{C} 8{ }^{2}$ and $\mathrm{C} 10$ as $S$ and $R$, respectively, ${ }^{72}$ confirming the tentative stereochemical assignment of carbons $\mathrm{C}^{2}$ and $\mathrm{C} 10$ in the prevailing epimers of natural NCCs, ${ }^{43}$ which was derived earlier in the course of the studies of the acid-induced isomerization of epi-5 to epi-10. ${ }^{37}$

The repeated observation of YCCs in extracts of senescent leaves and ripened fruit ${ }^{69,70,74,75}$ has been intriguing. Indeed, aerated aqueous or methanolic extracts of several senescent leaves converted $\boldsymbol{e p i - 1 1}$ (and its C16-epimer 11) cleanly to polar NCCs at ambient temperature, which were oxidized at C15 stereo- and regioselectively. These oxidized NCCs eliminated water (or methanol) under weakly acidic conditions to furnish the YCC $\mathbf{2 1 Z}$ selectively and in good yield. ${ }^{74}$ This finding led us to use a variety of leaf extracts (especially of the evergreen Spatiphyllum wallisii) to prepare YCCs from corresponding NCCs by a type of 'green synthesis' ${ }^{44}$ The identity of the 'oxidative activity' in leaves is still puzzling. ${ }^{74}$ However, the 'green synthesis' method with leaves of Sp. wallisii was also used for preparative oxidation of the semisynthetic 'pyro'-NCC epi-13 to the corresponding optically active 'pyro'-YCC $\mathbf{2 2 Z}\left(8^{2} S, 10 R, 15 Z-3^{2}\right.$-hydroxy-82-decarboxymethyl-1-formyl-19-oxo-19,N24-dihydrophyllobilene-c) (see Scheme 13). The methyl ester form Me-22Z crystallized readily and exhibited a dimer structure virtually superimposable to that of the YCC methyl ester Me-21Z. ${ }^{44}$

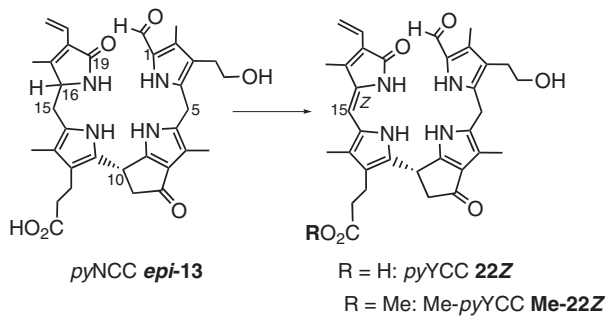

Scheme 13 PyNCC epi-13 is oxidized by aerated leaf extracts to pyYCC 22Z; the methyl ester Me-pyYCC Me-22Z crystallized in H-bonded and $\pi$-stacked dimers.

Along these lines, yellow PBs (phylloxanthobilins, PxBs) have been observed in extracts of senescent leaves of grapevine $^{51}$ and of an $A$. thaliana MES16-mutant, ${ }^{68}$ and were provisionally classified as type-II PxBs, proposed to represent oxidation products of the major isomeric DNCCs in each of these leaves. The major DNCC epi-23 of the C16'epi' series from senescent leaves of grapevine (named $V v$ - 


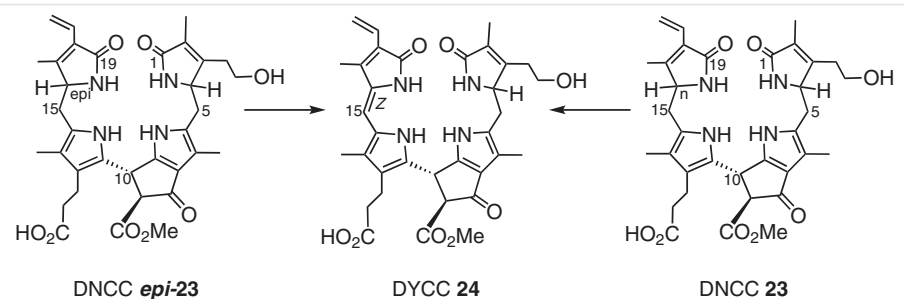

Scheme 14 DNCCs 23 and epi-23 are oxidized by chemical oxidants and by a puzzling 'oxidative activity' in leaves (e.g.) of Sp. wallisii at the 'western' moiety to the apparently common DYCC 24.

DNCC- $51^{51}$ and the C16-' $n$ '-epimer 23 of the A. thaliana mutant ${ }^{62}$ were used as substrates for selective oxidation by the 'green synthesis' method using leaves of Sp. wallisii. This furnished the corresponding dioxobilin-type YCCs (named $\mathrm{DYCC}^{\mathrm{Vv}}$ and DYCC ${ }^{\mathrm{At}}$ ) in roughly $70 \%$ yield (see Scheme 14).$^{76}$ The oxidation in the aerated leaf extract occurred again at the 'western' meso position, with remarkable regioselectivity, as observed earlier in the corresponding NCC-oxidation processes, ${ }^{74}$ thus, desaturating the stereo-differentiating asymmetric $\mathrm{C} 16$. In fact, the oxidation of both, the ' $n$ '- and 'epi'-DNCC, apparently furnished a single DYCC 24 ( $8^{2} S, 10 R, 15 Z-3^{2}$-hydroxy-1,19-dioxo-1,4,19,N24tetrahydrophyllobilene- $c$ ), suggesting the asymmetric $C 4$ to have the same absolute configuration in both DNCCs and their oxidation products. Hence, in the course of the oxidative deformylation of the corresponding epimeric FCC precursors by CYP89A9, C4 would be installed with the same absolute configuration in both DNCCs. ${ }^{60}$ On the basis of NMR-spectral analysis, these type-II PxBs were assigned their structures as $15 Z$-isomers. ${ }^{76}$ Interestingly, the CD- and luminescence spectral properties of $\mathbf{2 4}$ suggest a low tendency to associate into (homo)dimers even in apolar solvents, ${ }^{76}$ indicating the availability of the formyl-pyrrole unit in type-I PxBs (such as in the YCCs $21 Z$ and 22Z) to be a crucial factor in stabilizing their $\mathrm{H}$-bonded and $\pi$-stacked dimers. ${ }^{44,72}$

The blue-light-absorbing chromophore of YCCs is prone to further oxidation in the presence of air to pink-colored Chl catabolites (PiCCs), or type-I phylloroseobilins (PrBs), and PiCC $\mathbf{2 5}$ is a side product of the formation of the YCCs $\mathbf{2 1 Z}$ and $21 E$ by low-temperature DDQ or light-induced oxidation of NCCs. ${ }^{69,70}$ Traces of $\mathbf{2 5}$ are also found in extracts of senescent leaves of $C$. japonicum..$^{70}$ The most useful preparative method for the synthesis of $\mathbf{2 5}$ from $\mathbf{2 1 Z}$ turned out to be a two-step procedure encompassing (i) complexation of the YCC $\mathbf{2 1 Z}$ with $\mathrm{Zn}(\mathrm{II})$ ions in dimethylformamide solution, ${ }^{73}$ which, upon exposure to air, led to the clean formation of the blue $\mathrm{Zn}$ (II) complex $\mathbf{2 6}$ of the PiCC $\mathbf{2 5},{ }^{77}$ followed (ii) by removal of the $\mathrm{Zn}$ ion of $\mathbf{2 6}$ by treatment of its solution in acetonitrile with $20 \mathrm{mM}$ aqueous phosphate buffer ( $\mathrm{pH} 4.7$ ), furnishing 25 in an overall yield of $91 \% .{ }^{77}$ The structure of $\mathbf{2 5}$ was determined as a 10Z,15E-phyllobiladiene-b,c (see Scheme 15), on the basis of its NMR-spectral NOE data. A crystal structure analysis of $\mathbf{2 5}$ (as the potassi- um salt) confirmed this assignment of the molecular structure completely and showed $\mathbf{2 5}$ to crystallize as H-bonded and $\pi$-stacked pairs of enantiomers ( 25 is a racemate from equilibration at its acidified asymmetric $8^{2}$-position). ${ }^{77}$ Complexation of the effectively tridentate $\mathbf{2 5}$ by divalent transition-metal ions [such as $\mathrm{Zn}(\mathrm{II}), \mathrm{Ni}(\mathrm{II}), \mathrm{Cu}(\mathrm{II}), \mathrm{Cd}(\mathrm{II})$ ] occurs readily and induces the isomerization of the effective double bond $\mathrm{C} 10=\mathrm{C} 11$ to the $Z$-configuration in the blue complexes $\mathbf{M ( I I ) - 2 6}$ with the four divalent metal ions $\mathrm{M}(\mathrm{II}) .^{77,78}$ Solutions of the blue complexes $\mathbf{Z n - 2 6}$ and Cd-26 with the closed shell ions $\mathrm{Zn}(\mathrm{II})$ and $\mathrm{Cd}(\mathrm{II})$, respectively, exhibit an intense red luminescence, allowing for the quantitative analysis of $\mathrm{Zn}(\mathrm{II})$ and $\mathrm{Cd}(\mathrm{II})$ ions down to the $\mathrm{nM}$ range $^{77}$ (typical UV/Vis absorption spectra are collected in the reviews $\left.{ }^{5,8}\right)$.
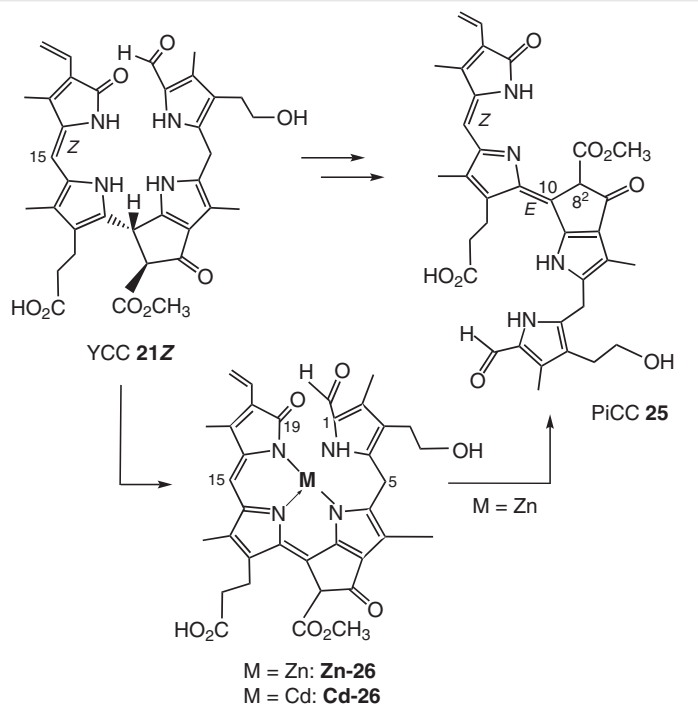

Scheme 15 YCC $21 Z$ slowly oxidizes with air in methanolic solution to PiCC 25. In the presence of air and Zn(II) ions $\mathbf{2 1 Z}$ is rapidly complexed and oxidized to the blue $\mathbf{Z n}$ complex $\mathbf{Z n - 2 6}$, from which $\mathbf{Z n}$ ions are removed by dilute phosphoric acid, furnishing the pink PiCC 25 in high yield.

In exploratory experiments, the dioxobilin-type $\mathrm{PxB}$ (DYCC) $\mathbf{2 4}$ was likewise revealed to have a pronounced tendency to oxidize in the presence of $\mathrm{Zn}(\mathrm{II})$ ions to the blue $\mathrm{Zn}(\mathrm{II})$ complex 27, from which the chiral and optically active type-II PrB (DPiCC) $\mathbf{2 8}$ was set free with dilute phos- 


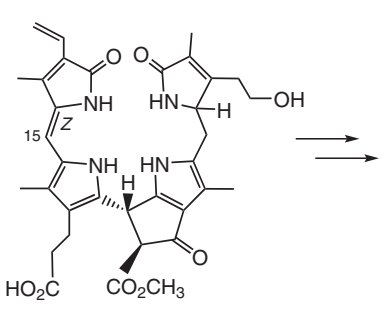

DYCC $24 Z$

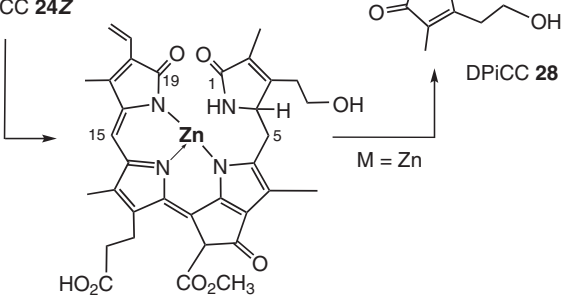

$\mathrm{Zn}-27$

Scheme 16 DYCC $24 Z$ slowly oxidizes with air in methanolic solution to DPiCC 28. Zn(II) ions rapidly complex $\mathbf{2 4 Z}$ and furnish the oxidized blue $\mathrm{Zn}$ complex $\mathbf{Z n - 2 7}$ in the presence of air. $\mathbf{Z n}$ ions are removed from Zn-27 by dilute phosphoric acid, furnishing the pink DPiCC 28.

phate buffer ( $\mathrm{pH} 4.7$ ) in 92\% yield (see Scheme 16). ${ }^{79}$ The weakly luminescent $\mathbf{2 8}$ bound $\mathrm{Zn}(\mathrm{II})$ ions with high affinity and furnished the red-luminescent $\mathrm{Zn}(\mathrm{II})$ complex 27 in practically quantitative yield.

\section{Conclusion and Outlook}

Chl breakdown has for a long time been considered to play a particular role in the recuperation of scarce plant nutrient, such as bioavailable forms of nitrogen. ${ }^{3}$ However, the earlier assumption that the plant would go after the four nitrogen atoms of the $\mathrm{Chl}$ molecules has received no support from the structures of the known PBs. ${ }^{5}$ Once $\mathrm{Chl}$ is broken down to the colorless PBs the further fate of these products of Chl degradation depends upon a variety of factors. In general, the colorless PBs found in extracts of senescent leaves do not account for the amount of Chl present in green leaves (see e.g. ${ }^{65}$ ) and known PBs do not accumulate for longer times in the tissue of senescent leaves and ripened fruit. ${ }^{47}$ The deduced in vivo disappearance of PBs may reflect their further degradation, physiological use involving further metabolic transformations, or extracellular transport processes. Typical PBs are excellent antioxidants (such as NCCs and YCCs) that are prone to undergo oxidation reactions. Their oxidation products, like the phyllochromobilins, may have a tendency to undergo further transformations. Indeed, the pink-colored PiCC $\mathbf{2 5}$ was not stable to storage in methanolic solution at ambient temperature. In exploratory experiments, $\mathbf{2 5}$ underwent a retro-Dieckmann reaction opening the $\beta$-keto-ester function of ring $\mathrm{E}$ to the corresponding tetrapyrrolic yellow dimethyl ester 29 (a 15Z-32-hydroxy-1,19-dioxo-1,4,19,N24-tetrahy- dro- $8^{1}, 8^{2}$-secophyllo-bilene-c) (see Scheme 17), which slowly decomposed to still uncharacterized further products. ${ }^{80}$ The relevance of such reactions for intracellular processes occurring in senescent leaves remains to be established. However, the further eventual cleavage of downstream PBs into bicyclic and monocyclic pyrrole derivatives would explain the observation in the Shio lab of apparently Chl-derived maleimides. ${ }^{81}$

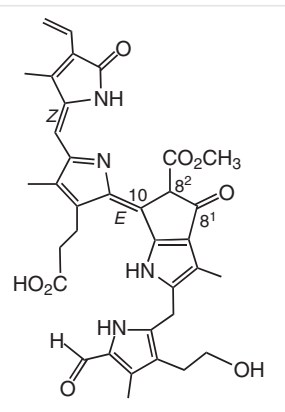

PiCC 25

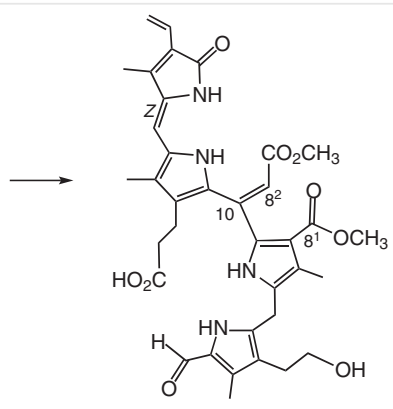

yellow seco-PB 29
Scheme 17 The pink Chl catabolite 25 undergoes retro-Dieckmann reaction at the Chl-derived ring $\mathrm{E}$ moiety readily, furnishing the yellow $8^{1}, 8^{2}$-seco-PB 29.

Because of the availability of the chemical structures of key bilin-type Chl catabolites ${ }^{1,5}$ several of the critical enzymes directly required in the breakdown process have been identified, establishing the common PAO/phyllobilin pathway of Chl breakdown in the so far studied angiosperms. ${ }^{6,32,82}$ The regulation of these important biochemical processes in the plants has attracted much interest and receives broad attention, currently, in order to obtain further insights into the plant's way of adjusting the cellular availability of $\mathrm{Chl}$ to the presence and absence of light, to biotic and biological external and internal stress, etc. ${ }^{31,32}$ Interestingly, in such studies, the occasional earlier bioinformaticsbased miss-assignments of enzymes have been corrected, such as the one of the $p$ FCC-hydroxylase TIC55. ${ }^{63}$ However, the ubiquitous enzymes active in the downstream part of the pathway, involved in attaching sugar units once or twice by glycosylation or esterification, are still unknown. ${ }^{6,51}$

Most recent studies in an ongoing collaboration with Thomas Müller have turned to investigating the structures of phyllobilins in Innsbruck, that occur in de-greened tissue of some gymnosperms, ferns, and other 'exotic' higher plants, such as Ginkgo biloba. ${ }^{83}$ Interestingly, we have been finding structural evidence from detailed spectroscopic work for unprecedented and intriguing deviations of Chl breakdown from the PAO/phyllobilin pathway in these families of higher plants. ${ }^{83}$ Bioinformatics methods have identified genes coding for activities related to those of PAO in green alga, ${ }^{32,84}$ and to those of PAO and RCCR in ferns and gymnosperms. ${ }^{84}$ The results of the structural and spectro- 
scopic studies will, again, invite follow-up investigations dealing with elucidating the corresponding new biochemical processes and their key regulatory processes.

An ever intriguing question in the field of Chl breakdown has concerned the plant biological 'why'., ${ }^{6,85}$ Earlier views on Chl breakdown considered the degradation of the potentially phototoxic Chl, and its removal from the plant cells, to represent a mere detoxification ${ }^{14,85}$ (metabolism of Chl has been deduced to have the same purpose in some herbivores, see e.g. ${ }^{86}$ ). In contrast, phyllobilins have become a topic of interest in their own right, lately, because of their possible hypothetical physiological roles in plant cells., ${ }^{5,45}$ Indeed, the chemical features of phyllobilins suggest a wide range of specific biological roles: (i) persistent fluorescent Chl catabolites, such as $h m$ FCCs, $b c$ FCCs, and $b c$ DFCCs, act as optical brighteners in fruit and leaves, making them blue fluorescent $t^{5,45,47}$ - this may represent a signal to frugivorous animals; 45 (ii) FCCs are effective sensitizers for the light-induced generation of singlet oxygen, ${ }^{87}$ a relevant cellular molecular signal; 88 (iii) some phyllochromobilins bind transition metals very effectively, suggesting a possible cellular role in heavy metal detoxification. ${ }^{78}$ (iv) phyllochromobilins and their metal complexes are intensely colored compounds, ${ }^{78}$ adding to the list of pigments in plant cells; ${ }^{89}(\mathrm{v})$ NCCs and YCCs are very effective amphiphilic antioxidants ${ }^{56}$ that extend the repertoire of plant cells in their control and neutralization of reactive oxygen species; (vi) bicyclo-PBs $(b c \mathrm{PBs})^{51,90}$ and other 'persistent' $h m \mathrm{PBs}^{45}$ are heterocyclic natural products with structures that may make them attractive as anti-infective agents in plants and in other applications. ${ }^{51}$ Furthermore, phyllochromobilins feature structures strikingly related to those of some (heme-derived) natural bilins, specifically when taking into account some colored type-II or dioxobilin-type PBs. ${ }^{5,76}$ Hence, phyllochromobilins may play crucial roles as inhibitors of bilin-dependent enzymes, e.g., in photoregulation, ${ }^{91}$ or as effectors, in their own right, in such enzymes. Clearly, the discovery of the presumed, but still elusive plant-biological roles of phyllobilins is an exciting scientific quest, as is the possible use of phyllobilins in pharmacological applications. $^{5}$

\section{Acknowledgment}

I would like to thank Thomas Müller and Stefan Hörtensteiner for their very fruitful collaborations, and have enjoyed working with a group of dedicated and talented doctoral and post-doctoral coworkers, whose names are listed in the references. Our work in the field of chlorophyll breakdown has been supported by the Austrian National Science Foundation (FWF), currently by the project P-28522, as well as by the Interreg IV Italy-Austria program (project Nr. 5345 "Biophytirol").

\section{References}

(1) Kräutler, B.; Matile, P. Acc. Chem. Res. 1999, 32, 35.
(2) Hendry, G. A. F.; Houghton, J. D.; Brown, S. B. New Phytol. 1987, 107, 255.

(3) Matile, P. Chimia 1987, 41, 376.

(4) Kräutler, B.; Jaun, B.; Bortlik, K.; Schellenberg, M.; Matile, P. Angew. Chem. Int. Ed. 1991, 30, 1315.

(5) Kräutler, B. Angew. Chem. Int. Ed. 2016, 55, 4882.

(6) Hörtensteiner, S.; Kräutler, B. Biochim. Biophys. Acta 2011, 1807, 977.

(7) Hörtensteiner, S. Plant Mol. Biol. 2013, 82, 505.

(8) Kräutler, B. Chem. Soc. Rev. 2014, 43, 6227.

(9) The Chemistry of Linear Oligopyrroles and Bile Pigments; Falk, H., Ed.; Springer: Wien, 1989.

(10) Wilks, A. Heme Degradation: Mechanistic and Physiological Implications, In Tetrapyrroles: Birth, Life and Death; Warren, M. J.; Smith, A. G., Ed.; Landes Bioscience: Austin Texas, 2008, 101115.

(11) Thomas, H.; Bortlik, K.; Rentsch, D.; Schellenberg, M.; Matile, P. New Phytol. 1989, 111, 3.

(12) Bortlik, K.; Peisker, C.; Matile, P. J. Plant Physiol. 1990, 136, 161.

(13) Kräutler, B.; Jaun, B.; Amrein, W.; Bortlik, K.; Schellenberg, M.; Matile, P. Plant Physiol. Biochem 1992, 30, 333.

(14) Matile, P.; Hörtensteiner, S.; Thomas, H.; Kräutler, B. Plant Physiol. 1996, 112, 1403.

(15) Brown, S. B.; Houghton, J. D.; Hendry, G. A. F. Chlorophyll Breakdown, In Chlorophylls; Scheer, H., Ed.; CRC Press: Boca Raton, 1991, 465-489.

(16) Wilks, A.; Ikeda-Saito, M. Acc. Chem. Res. 2014, 47, 2291.

(17) Matile, P.; Schellenberg, M.; Peisker, C. Planta 1992, 187, 230.

(18) Hörtensteiner, S.; Vicentini, F.; Matile, P. New Phytol. 1995, 129, 237.

(19) Mühlecker, W.; Ongania, K. H.; Kräutler, B.; Matile, P.; Hörtensteiner, S. Angew. Chem. Int. Ed. 1997, 36, 401.

(20) (a) Mühlecker, W.; Kräutler, B. Plant Physiol. Biochem. 1996, 34, 61. (b) Mühlecker, W.; Kräutler, B.; Ginsburg, S.; Matile, P. Helv. Chim. Acta 1993, 76, 2976.

(21) Mühlecker, W.; Kräutler, B.; Moser, D.; Matile, P.; Hörtensteiner, S. Helv. Chim. Acta 2000, 83, 278.

(22) (a) Engel, N.; Jenny, T. A.; Mooser, V.; Gossauer, A. FEBS Lett. 1991, 293, 131. (b) Engel, N.; Curty, C.; Gossauer, A. Plant Physiol. Biochem. 1996, 34, 77.

(23) Kräutler, B.; Mühlecker, W.; Anderl, M.; Gerlach, B. Helv. Chim. Acta 1997, 80, 1355.

(24) Iturraspe, J.; Gossauer, A. Tetrahedron 1992, 48, 6807.

(25) Iturraspe, J.; Engel, N.; Gossauer, A. Phytochem. 1994, 35, 1387.

(26) Rodoni, S.; Mühlecker, W.; Anderl, M.; Kräutler, B.; Moser, D.; Thomas, H.; Matile, P.; Hörtensteiner, S. Plant Physiol. 1997, 115 , 669.

(27) Pružinska, A.; Tanner, G.; Anders, I.; Roca, M.; Hörtensteiner, S. Proc. Natl. Acad. Sci. USA 2003, 100, 15259.

(28) Pružinska, A.; Anders, I.; Aubry, S.; Schenk, N.; Tapernoux-Lüthi, E.; Müller, T.; Kräutler, B.; Hörtensteiner, S. Plant Cell 2007, 19, 369.

(29) Hörtensteiner, S.; Rodoni, S.; Schellenberg, M.; Vicentini, F.; Nandi, O. I.; Qui, Y. L.; Matile, P. Plant Biol. 2000, 2, 63.

(30) Hörtensteiner, S.; Wüthrich, K. L.; Matile, P.; Ongania, K. H.; Kräutler, B. J. Biol. Chem. 1998, 273, 15335.

(31) Kräutler, B.; Hörtensteiner, S. Handbook of Porphyrin Science; Ferreira, G. C.; Kadish, K. M.; Smith, K. M.; Guilard, R., Ed.; World Scientific Publishing: USA, 2013, 117-185.

(32) Kuai, B.; Chen, J.; Hörtensteiner, S. J. Exp. Bot. 2017, 69, 751.

(33) Oberhuber, M.; Kräutler, B. ChemBiochem 2002, 3, 104.

(34) Oberhuber, M.; Berghold, J.; Kräutler, B. Angew. Chem. Int. Ed. 2008, 47, 3057. 
(35) Dammeyer, T.; Frankenberg-Dinkel, N. Photochem. Photobiol. Sci. 2008, 7, 1121.

(36) (a) Sugishima, M.; Okamoto, Y.; Noguchi, M.; Kohchi, T.; Tamiaki, H.; Fukuyama, K. J. Mol. Biol. 2010, 402, 879. (b) Wüthrich, K. L.; Bovet, L.; Hunziker, P. E.; Donnison, I. S.; Hörtensteiner, S. Plant J. 2000, 21, 189.

(37) Oberhuber, M.; Berghold, J.; Breuker, K.; Hörtensteiner, S.; Kräutler, B. Proc. Natl. Acad. Sci. USA 2003, 100, 6910.

(38) Müller, T.; Vergeiner, S.; Kräutler, B. Int. J. Mass Spectrom. 2014, 365-366, 48-55.

(39) Kräutler, B. The Porphyrin Handbook; Kadish, K. M.; Smith, K. M.; Guilard, R., Ed.; Elsevier: Oxford, 2003, 183-209.

(40) Berghold, J.; Breuker, K.; Oberhuber, M.; Hörtensteiner, S.; Kräutler, B. Photosynth. Res. 2002, 74, 109.

(41) Oberhuber, M.; Berghold, J.; Mühlecker, W.; Hörtensteiner, S.; Kräutler, B. Helv. Chim. Acta 2001, 84, 2615.

(42) Curty, C.; Engel, N. Phytochem. 1996, 42, 1531.

(43) Moser, S.; Scherzer, G.; Kräutler, B. Chem. Biodiversity 2017, 14, e1700368.

(44) Li, C.; Wurst, K.; Berghold, J.; Podewitz, M.; Liedl, K. R.; Kräutler, B. Chem. Eur. J. 2018, 24, 2987.

(45) Moser, S.; Müller, T.; Ebert, M.-O.; Jockusch, S.; Turro, N. J.; Kräutler, B. Angew. Chem. Int. Ed. 2008, 47, 8954.

(46) (a) Vergeiner, C.; Banala, S.; Kräutler, B. Chem. Eur. J. 2013, 19, 12294. (b) Müller, T.; Kräutler, B. Gerontology 2011, 57, 521.

(47) Moser, S.; Müller, T.; Holzinger, A.; Lütz, C.; Jockusch, S.; Turro, N. J.; Kräutler, B. Proc. Natl. Acad. Sci. USA 2009, 106, 15538.

(48) Moser, S.; Müller, T.; Holzinger, A.; Lütz, C.; Kräutler, B. Chem. Eur. J. 2012, 18, 10873.

(49) Banala, S.; Moser, S.; Müller, T.; Kreutz, C.; Holzinger, A.; Lütz, C.; Kräutler, B. Angew. Chem. Int. Ed. 2010, 49, 5174.

(50) Kräutler, B.; Banala, S.; Moser, S.; Vergeiner, C.; Müller, T.; Lütz, C.; Holzinger, A. FEBS Lett. 2010, 584, 4215.

(51) Erhart, T.; Mittelberger, C.; Liu, X. J.; Podewitz, M.; Li, C. J.; Scherzer, G.; Stoll, G.; Valls, J.; Robatscher, P.; Liedl, K. R.; Oberhuber, M.; Kräutler, B. Chem. Eur. J. 2018, in press; DOI: 10 1002/chem.201803128.

(52) Moser, S.; Müller, T.; Oberhuber, M.; Kräutler, B. Eur. J. Org. Chem. 2009, 21.

(53) Kräutler, B. Photochem. Photobiol. Sci. 2008, 7, 1114.

(54) (a) Berghold, J.; Eichmüller, C.; Hörtensteiner, S.; Kräutler, B. Chem. Biodiversity 2004, 1, 657. (b) Berghold, J.; Müller, T.; Ulrich, M.; Hörtensteiner, S.; Kräutler, B. Monatsh. Chem. 2006, 137, 751. (c) Pružinska, A.; Tanner, G.; Aubry, S.; Anders, I.; Moser, S.; Müller, T.; Ongania, K.-H.; Kräutler, B.; Youn, J.-Y.; Liljegren, S. J.; Hörtensteiner, S. Plant Physiol. 2005, 139, 52. (d) Erhart, T.; Mittelberger, C.; Vergeiner, C.; Scherzer, G.; Holzner, B.; Robatscher, P.; Oberhuber, M.; Kräutler, B. Chem. Biodiversity 2016, 13, 1441.

(55) Roiser, M.; Müller, T.; Kräutler, B. J. Agric. Food Chem. 2015, 63, 1385.

(56) Müller, T.; Ulrich, M.; Ongania, K.-H.; Kräutler, B. Angew. Chem. Int. Ed. 2007, 46, 8699.

(57) (a) Scherl, M.; Müller, T.; Kräutler, B. Chem. Biodiversity 2012, 9, 2605. (b) Ríos, J. J.; Roca, M.; Pérez-Gálvez, A. J. Agric. Food Chem. 2014, 62, 10576. (c) Vergara-Dominguez, H.; Rios, J. J.; Gandul-Rojas, B.; Roca, M. Food Chem. 2016, 212, 604.

(58) Losey, F. G.; Engel, N. J. Biol. Chem. 2001, 276, 8643.

(59) Müller, T.; Rafelsberger, M.; Vergeiner, C.; Kräutler, B. Angew. Chem. Int. Ed. 2011, 50, 10724.

(60) Christ, B.; Süssenbacher, I.; Moser, S.; Bichsel, N.; Egert, A.; Müller, T.; Kräutler, B.; Hörtensteiner, S. Plant Cell 2013, 25, 1868.
(61) Süssenbacher, I.; Kreutz, C.; Christ, B.; Hörtensteiner, S.; Kräutler, B. Chem. Eur. J. 2015, 21, 11664.

(62) Christ, B.; Schelbert, S.; Aubry, S.; Süssenbacher, I.; Müller, T.; Kräutler, B.; Hörtensteiner, S. Plant Physiol. 2012, 158, 628.

(63) Hauenstein, M.; Christ, B.; Das, A.; Aubry, S.; Hörtensteiner, S. Plant Cell 2016, 28, 2510.

(64) Süssenbacher, I.; Hörtensteiner, S.; Kräutler, B. Angew. Chem. Int. Ed. 2015, 54, 13777.

(65) Mittelberger, C.; Yalcinkaya, H.; Pichler, C.; Gasser, J.; Scherzer, G.; Erhart, T.; Schumacher, S.; Holzner, B.; Janik, K.; Robatscher, P.; Müller, T.; Kräutler, B.; Oberhuber, M. J. Agric. Food Chem. 2017, 65, 2651.

(66) Christ, B.; Hauenstein, M.; Hortensteiner, S. Plant J. 2016, 88, 505.

(67) Ríos, J. J.; Pérez-Gálvez, A.; Roca, M. Food Res. Int. 2014, 65, 255.

(68) Süßenbacher, I.; Christ, B.; Hörtensteiner, S.; Kräutler, B. Chem. Eur. J. 2014, 20, 87.

(69) Moser, S.; Ulrich, M.; Müller, T.; Kräutler, B. Photochem. Photobiol. Sci. 2008, 7, 1577.

(70) Ulrich, M.; Moser, S.; Müller, T.; Kräutler, B. Chem. Eur. J. 2011, $17,2330$.

(71) Lightner, D. A. Progr. Chem. Org. Nat. Prod. 2013, 98, 1.

(72) Li, C. J.; Wurst, K.; Jockusch, S.; Gruber, K.; Podewitz, M.; Liedl, K. R.; Kräutler, B. Angew. Chem. Int. Ed. 2016, 55, 15760.

(73) Li, C.; Kräutler, B. J. Porphyrins Phthalocyanines 2016, 20, 388.

(74) Vergeiner, C.; Ulrich, M.; Li, C.; Liu, X.; Müller, T.; Kräutler, B. Chem. Eur. J. 2015, 21, 136.

(75) (a) Wakana, D.; Kato, H.; Momose, T.; Sasaki, N.; Ozeki, Y.; Goda, Y. Tetrahedron Lett. 2014, 55, 2982. (b) Roca, M.; Rios, J. J.; Chahuaris, A.; Perez-Galvez, A. Food Res. Int. 2017, 100, 332.

(76) Li C. J.; Erhart T.; Liu X. J.; Kräutler B. manuscript in preparation.

(77) Li, C.; Ulrich, M.; Liu, X.; Wurst, K.; Müller, T.; Kräutler, B. Chem. Sci. 2014, 5, 3388.

(78) Li, C.; Kräutler, B. Dalton Trans. 2015, 44, 10116.

(79) Li C. J.; Kräutler B. manuscript in preparation.

(80) Li C. J.; Kräutler B.; unpublished work.

(81) Suzuki, Y.; Shioi, Y. Plant Cell Physiol. 1999, 40, 909.

(82) Tanaka, R.; Tanaka, A. Biochim. Biophys. Acta 2011, 1807, 968.

(83) Erhart, T.; Vergeiner, S.; Kräutler, B.; Müller, T. Angew. Chem. Int. Ed. 2018, in press; DOI: 10 1002/anie.201807818.

(84) Thomas, H.; Huang, L.; Young, M.; Ougham, H. BMC Evol. Biol. 2009, 9, 163.

(85) Matile, P.; Duggelin, T.; Schellenberg, M.; Rentsch, D.; Bortlik, K.; Peisker, C.; Thomas, H. Plant Physiol. Biochem. 1989, 27, 595.

(86) Kashiyama, Y.; Yokoyama, A.; Kinoshita, Y.; Shoji, S.; Miyashiya, H.; Shiratori, T.; Suga, H.; Ishikawa, K.; Ishikawa, A.; Inouye, I.; Ishida, K.; Fujinuma, D.; Aoki, K.; Kobayashi, M.; Nomoto, S.; Mizoguchi, T.; Tamiaki, H. Proc. Natl. Acad. Sci. USA 2012, 109, 17328.

(87) Jockusch, S.; Turro, N. J.; Banala, S.; Kräutler, B. Photochem. Photobiol. Sci. 2014, 13, 407.

(88) Apel, K.; Hirt, H. Annu. Rev. Plant Biol. 2004, 55, 373.

(89) Buchanan, B. B.; Gruissem, W.; Jones, R. L. Biochemistry and Molecular Biology of Plants; Am. Soc. Plant Physiologists: Rockville, 2001.

(90) Scherl, M.; Müller, T.; Kreutz, C.; Huber, R. G.; Zass, E.; Liedl, K. R.; Kräutler, B. Chem. Eur. J. 2016, 22, 9498.

(91) Demmig-Adams, B.; Adams III, W. W.; Mattoo, A. Photoprotection Photoinhibition Gene Regulation and Environment, In Advances in Photosynthesis and Respiration; Springer: Dordrecht, 2006. 